\title{
Potenciando una mirada joven hacia el patrimonio
}

pasado mes de marzo, en Gijón (Asturias), tuvo lugar un intercambio juvenil que pretendió ser un acercamiento de jóvenes de Argentina, Italia, Grecia y España con el rico patrimonio cultural de sus regiones a través de la adquisición de habilidades relacionadas con el emprendimiento. Esta actividad pertenece al proyecto europeo Erasmus+ en el que se enmarca Youth SuccesSors, una iniciativa de desarrollo de capacidades de los jóvenes para la promoción del patrimonio cultural y territorial.

Lara Granado Penín, Katia Rodríguez Álvarez | Magenta Consultoría Projects

URL de la contribución <http://www.iaph.es/revistaph/index.php/revistaph/article/view/4400>

Este proyecto se desarrollaba, además, en el Año Europeo del Patrimonio Cultural 2018, cuyo objetivo era concienciar a las personas a descubrir y participar del patrimonio cultural de Europa, buscando involucrar a la ciudadanía en eventos orientados a hacer acccesible el patrimonio cultural y a reforzar el sentido de pertenencia al espacio europeo común. El patrimonio cultural, en constante evolución, desempeña un papel fundamental en la construcción del futuro de Europa como una comunidad libre de prejuicios, acogedora y simpatizante con todos y requiere, por tanto, del compromiso de todos.

El objetivo del intercambio fue potenciar la promoción territorial y el turismo responsabe a la vez que fomentar la empleabilidad de los jóvenes a partir de la valoración de los recursos que sus países pueden ofrecer. Los jóvenes muchas veces no tienen claro cuáles son los instrumentos que tienen a su disposición en cuanto al patrimonio cultural nacional se refiere. Precisamente es por esta cuestión por la que se implementa esta iniciativa europea. Que los jóvenes puedan adquirir habilidades empresariales es de vital importancia, es la clave para que tomen la iniciativa en trabajos relacionados con la preservación del medio ambiente y del patrimonio cultural.

Otras iniciativas llevadas a cabo en el mismo sentido serían Youth For Heritage, que anima a la juventud a participar en proyectos relacionados con el patrimonio cultural de su país o región, desarrollando capacidades para protegerlo y defenderlo, y Heritage At School que promueve un mayor conocimiento patrimonial de Europa en las escuelas.

El proyecto Youth SuccesSors, del que formaban parte los 4 países previamente mencionados, entre los que se encontraba como socia Magenta Consultoría Projects representando a España en colaboración con otros 5 socios, además del intercambio desarrollado la semana del 3 al 9 de marzo de 2019, que fue dirigido a jóvenes entre 18 y 30 años, incluyó actividades formativas en Grecia e Italia donde se formó a trabajadores de juventud en esta materia. Tanto en estas acciones como en el propio intercambio se pretendía poner en valor aspectos como la ciudadanía activa, el pensamiento crítico, la toma de responsabilidad en la preservación de los recursos y promocionar aspectos como la biodiversidad, igualdad e interculturalidad.

En este tipo de proyectos los socios se encargan de la estructura, organización, contacto con las personas interesadas en participar, de la implementación y de asegurarse, tras la finalización, que el proyecto sigue presente en la sociedad, de alguna forma $u$ otra (publicaciones periódicas sobre este tipo de iniciativas o la promoción de ideas por medio de las personas que acudieron a las actividades). En cuanto a qué se aporta, primero, y qué se recibe, después, hablaríamos de una sinergia entre organizaciones de distintas culturas, las cuales se unen por un mismo objetivo: luchar y defender algo tan preciado como es el patrimonio cultural, no solo a nivel nacional, sino a también europeo. Todas las organizaciones participantes crean una amplia red de contactos que 


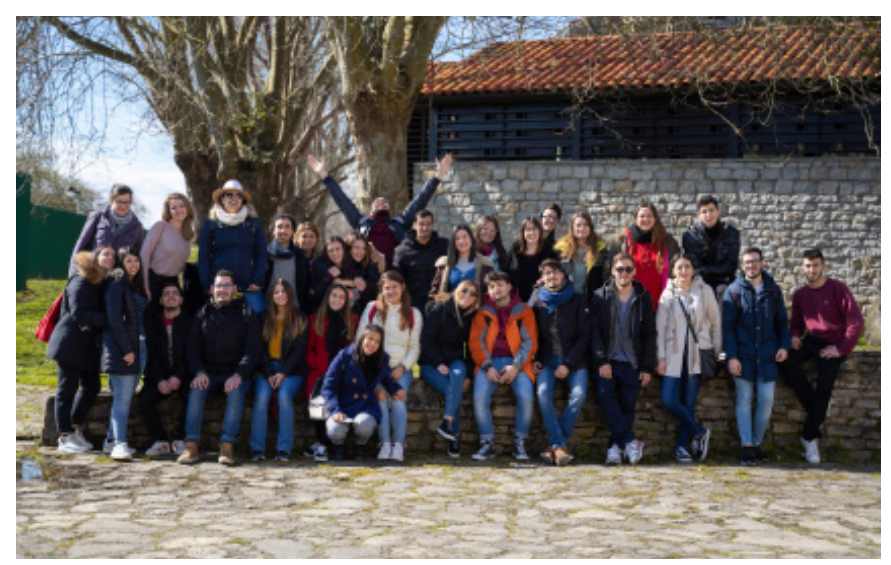

fotos Magenta Consultoría Projects

les será útil en algún momento futuro, enriqueciendo la comunidad europea (y no europea, puesto que a veces participan países no comunitarios), el sentido de la diversidad y la participación entre culturas.

En el caso de Magenta Consultoría Projects, lo que podemos aportarles a los jóvenes que participaron en esta actividad es nuestra experiencia personal con el patrimonio cultural de nuestra región. En nuestros proyectos de movilidad siempre se promueven las visitas a puntos patrimoniales clave, ya sean en relación a los monumentos más importantes o a la gastronomía típica del lugar, erc.

Una de las actividades del intercambio estuvo enfocada a presentarles asociaciones o empresas que a día de hoy se dedican a promover iniciativas culturales relevantes. En este caso, tuvieron la oportunidad de hablar con 30 días en bici, campaña que pretende promover el uso diario de la bicicleta como herramienta de cambio social y mejora de la calidad de vida, que ha tenido tanto éxito que ha sido replicada en otras ciudades del globo.

Otro componente importante fueron las visitas culturales que se programaron a lugares emblemáticos de la ciudad. Por un lado, se escogió visitar LABoral, Centro de Arte y Creación Industrial, un espacio para fomentar expresiones artísticas de autores locales; así como el Muséu del Pueblu d'Asturies, que cuenta con colecciones etnográficas, documentos, instrumentos y fotogra-

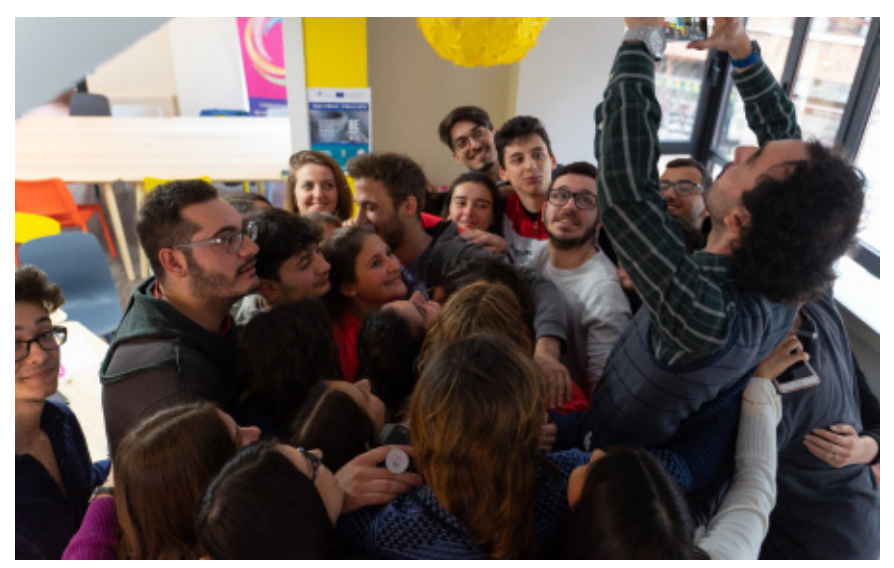

fías donde se conservan y difunden las memorias del pueblo asturiano. Ambos centros fueron escogidos por su amplia labor en la conservación del patrimonio cultural de la región, y que acogen frecuentemente exposiciones tanto artística como memoriales.

Sin duda, lo que nos dice esta experiencia es que a los jóvenes les interesa el patrimonio y la historia que les rodea, pero que muchas veces no conocen los recursos que poseen. Por ello, concienciarlos y dotarlos de herramientas adecuadas se vuelve esencial para aprovechar los recursos que, si se conservan y valorizan con responsabilidad y conciencia, son la riqueza inagotable que puede garantizar la prosperidad y una variedad de oportunidades laborales y empresariales relacionadas con el turismo y la promoción territorial no solo a nivel regional o nacional, sino también al nivel de la comunidad europea. 